\title{
Kinetics of structural rust transformation in environments containing chloride and $\mathrm{SO}_{2}$
}

\author{
J.L. Rendón and A. Valencia*
}

\begin{abstract}
The behavior of the rusts produced on low carbon steel exposed in industrial atmospheres, at different distances from the sea, was studied by simulating the wetting-drying cycle in a CEBELCOR type apparatus. Coupons electrode potential was monitored and rust layer was analyzed by gravimetric techniques, optical microscopy and Mössbauer spectroscopy. A particular chloride/sulfur ratio in the atmosphere was found, for which there is a particular behavior in rust formation. For this ratio, corrosion rates were much less than expected. It is postulated a kinetic mechanism for rust layer formation as the origin of this special behavior. An electrode potential similar to that in a weathering steel was observed, this is reflected in the low corrosion rate obtained. The proposed kinetic mechanism for rust formation under these exposure conditions enables new research lines on layer formation and the development of protective rust for industrial marine atmospheres.
\end{abstract}

Keywords Atmospheric Corrosion. Sulphur dioxide/chloride relation. Rust formation. Potential measuring. Simulation test.

\section{Cinética de las transformaciones químicas y estructurales de las herrumbres expuestas en ambientes con cloruros y $\mathrm{SO}_{2}$}

\begin{abstract}
Resumen Se estudió el comportamiento de las herrumbres de un acero de bajo carbono expuesto en la simulación de atmósferas industriales con diferentes distancias al mar, con del ciclo de humectación y secado en el ensayo CEBELCOR y en soluciones representativas de las atmósferas en cuestión. Se hizo seguimiento del potencial de electrodo de los cuerpos de prueba y se analizó la capa de productos de corrosión por técnicas gravimétricas, microscopía óptica y espectroscopía Mössbauer. Se determinó un valor de cloruros y sulfatos en la atmósfera que genera un comportamiento particular en la formación de la herrumbre, presentando velocidades de corrosión menores a las esperadas para el tenor de agentes agresivos, y se postuló un mecanismo cinético en la formación de la película çomo causante del fenómeno particular. Se observó un comportamiento del potencial próximo al de un acero autoprotector, que se refleja en una menor velocidad de corrosión. La propuesta del mecanismo cinético de la formación de herrumbres en estas condiciones de exposición, posibilita nuevas líneas de estudio en el área del control de la formación de películas protectoras para atmósferas marina e industrial.
\end{abstract}

Palabras clave Corrosión atmosférica. Relación dióxido de azufre/cloruros. Formación de herrumbres. Medidas de potencial. Ensayo de simulación.

\section{INTRODUCTION}

Magnitude of atmospheric corrosion is directly related to, among other variables, chloride and sulfur dioxide content in the environment, and a higher damage rate is expected as that content increases ${ }^{[1]}$.

Research in this area is directed at knowing corrosion products nature, its dependence on exposure conditions and formation mechanisms, as an approach to the relation between the rust layer and its isolating capacity, which inhibits the corrosion phenomenon. Relationships have been found between constituents type, their relative quantities in the rust layer and material corrosion rate, not only because of its morphology, but also because of the critical kinetic path for the formation of each one, a fundamental aspect for the evaluation of corrosion rate $\mathrm{e}^{[2-4]}$.

This relationship was corroborated in the present work and it was also confirmed a corrosion inhibition phenomenon due to the combined

(*) Materials Engineering Department, University of Antioquia, A.A. 1226, Medellín. Colombia. 
action of chloride and sulfur dioxide, giving lesser corrosion values than expected for the pollutants total content. This had been observed previously in field ${ }^{[5]}$ and laboratory studies ${ }^{[6]}$.

Based on these results an approximation to the process kinetics was achieved, the mechanisms which lead to constituent formation were identified as well as the rust that implies less corrosion rate in the particular case of the synergistic action of chloride and sulfur dioxide.

\section{EXPERIMENTAL PROCEDURE}

Basic aspects of the experimental procedure followed in this study are presented.

\subsection{Simulating solutions}

Solutions simulated industrial atmosphere conditions, with variations in chloride content, that represent different distances from the sea. Six receptacles were used having the concentrations indicated in table I.

\subsection{Material}

The study was performed with AISI-SAE 1008 carbon steel.

\subsection{Test general conditions}

A device belonging to the Corrosion and Protection Group, University of Antioquia, was used. Wetting and drying periods were 13 and 28 min respectively. Drying temperature on the coupons was approximately $45^{\circ} \mathrm{C}$.

The aforementioned phenomenon has been detected in marine industrial atmospheres and in laboratory studies using solutions with concentrations around $1 * 10^{-3}$ molar of $\mathrm{NaCl}$ and $1 * 10^{-4}$ molar of $\mathrm{NaHSO}_{3}$. These solutions have

Table l. Corrosive agents concentrations in the simulating solutions

Tabla I. Concentraciones de agentes corrosivos en las soluciones de simulación

\begin{tabular}{|c|c|c|c|c|c|c|}
\hline RECEPTACLE & 2 & 1 & 3 & 4 & 5 & 6 \\
\hline $\mathrm{NaCl} * 10^{-3} \mathrm{MOLAR}$ & 1 & 1 & 1.25 & 1.5 & 1.75 & 3 \\
\hline $\mathrm{NaSO}_{4} * 10^{-4} \mathrm{MOLAR}$ & 1.25 & 1 & 1 & 1 & 1 & 2 \\
\hline$[\mathrm{NaCl}] /\left[\mathrm{NaSO}_{4}\right]$ & 0.8 & 1 & 1.25 & 1.5 & 1.75 & 1.5 \\
\hline
\end{tabular}

been traditionally considered as representatives of the type of atmospheres where the phenomenon was detected in atmospheric conditions.

Potentials were measured at the entrance and exit of the coupon of the simulating solution. A saturated calomel electrode and a high impedance multimeter were used.

Based on previous studies ${ }^{[7]}$, it was determined that there are important variations on the potential for 10,20 and $65 \mathrm{~d}$. Coupons were removed after these periods to characterize rusts for those particular cases and have an approximation to their evolution with time.

The methodology employed was: corrosion rate calculation by gravimetric techniques, constituents quantitative determination by Mössbauer spectroscopy at room temperature and optical microscopy of the coupons cross section.

\section{RESULTS}

Figure 1a presents the electrode potential evolution of systems $1,2,3$ and 6 , and figure $1 \mathrm{~b}$ for the system 4 , measured at the coupon exit from the simulating solution.

In table II corrosion rates are presented for the six evaluated systems and standard deviations among coupons.

For a better understanding of the information analysis, figure 2 presents the metalography of 3, 4 and 5 systems for 10, 20 and $65 \mathrm{~d}$ of testing, that typify rust layer morphology and evolution with time.

In table III are shown the results of magnetite contents in rusts studied by Mössbauer spectroscopy. Values for other constituents are not presented because of space lack.

\section{ANALYSIS OF RESULTS}

Potential evolution is the first sign of an anomalous behavior in receptacle 4 system. The potential measurements start with negative values in the higher corrosion rate systems 3,5 and 6. After day $20^{\text {th }}$ a change occurs in rust behavior and kinetics, revealed by the potentials increasing up to positive values. It means low corrosion rates.

As it is shown in table II, system 4 breaks the trend of increasing in corrosion rate with chloride content rise in the simulating solution. Values are lower than in receptacles 3 and 5, its next neighbors. 


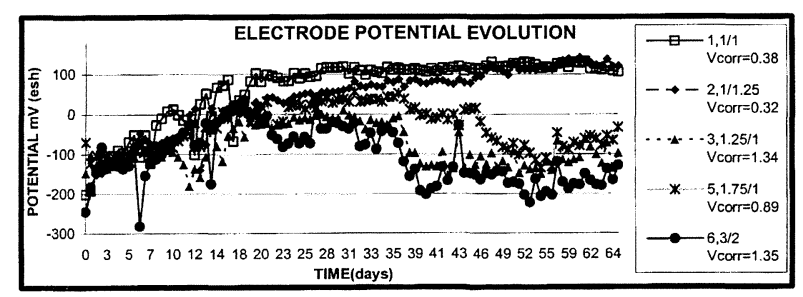

Figure 1a

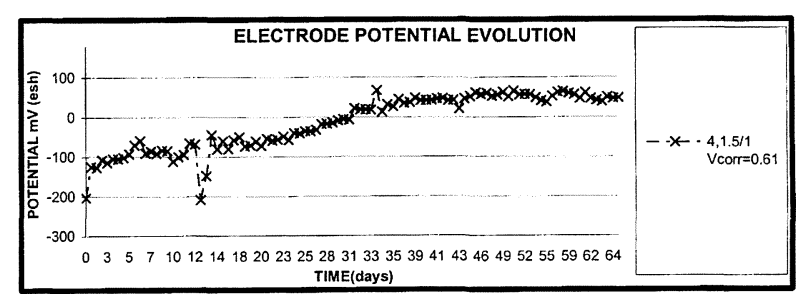

Figure 1b

Figure 1. Evolution potential at the exit with testing time. $\mathrm{mV}$ (Esh: Standard Hydrogen Electrode). a) Systems 1, 2, 3, 5 and 6. b) System 4.

Figura 1. Evolución del potencial de salida en el tiempo de ensayo. $m V$ (Esh: Electrodo Normal de Hidrógeno. a) Sistemas 1, 2, 3, 5 y 6. b) Sistema 4.

\section{KINETIC CONSIDERATIONS AND CORROSION RATE}

Based on the morphologies above-described and the rust metallography show in figure 2 , the following kinetic aspects, which lead to corrosion inhibition, are proposed. The explanation is given to answer two basic questions.

Which mechanism did provoke the aforementioned behaviors? To clearly answer this question every behavior type is explained, based on the observed results for the various variables evolution.

It is necessary to accept sulfate nests existence in all simulation conditions and their proliferation phenomenology by highly concentrated $\mathrm{H}_{2} \mathrm{SO}_{4}$ explosions, the acid regeneration cycle and the presence of akaganehite as a result of chloride content, that is based on previous research ${ }^{[8]}$.

In group 1, composed by systems 1, 2 and 3, metallographic observation showed a nest's morphology related to black nodules in the image. They grow preferentially towards rust layer and are surrounded by an orange phase related to lepidocrocite. At a close distance, yellow phase growth was observed, which is sign of goethite formation.

The acid regeneration cycle in the sulfate nests generated oxygen enrichment in the adjacent area, and allowed the rapid rust transformation and also the transformation of the green complexes that surrounded the lepidocrocite nest. It also inhibited, in some extent, the transformation to magnetite. These zones close to the nests, as

Table II. Corrosion rates mean values calculated by gravimetric techniques ( $\mu \mathrm{m} /$ day of testing), and their standard deviations

Tabla II. Velocidad de corrosión promedio calculada por técnica gravimétrica ( $\mu \mathrm{m} /$ día de ensayo), y algunas desviaciones estándar

\begin{tabular}{|c|c|c|c|c|c|c|c|c|c|c|c|c|}
\hline \multirow{3}{*}{$\begin{array}{l}\text { RECEPTACLE } \\
\frac{[\mathrm{NaCl}] /\left[\mathrm{SO}_{4}^{=}\right]}{\text {DAYS }}\end{array}$} & \multicolumn{2}{|c|}{2} & \multicolumn{2}{|c|}{1} & \multicolumn{2}{|c|}{3} & \multicolumn{2}{|c|}{4} & \multicolumn{2}{|c|}{5} & \multicolumn{2}{|c|}{6} \\
\hline & \multicolumn{2}{|c|}{$1 / 1.25=0.8$} & \multicolumn{2}{|c|}{1} & \multicolumn{2}{|c|}{1.25} & \multicolumn{2}{|c|}{1.5} & \multicolumn{2}{|c|}{1.75} & \multicolumn{2}{|c|}{$3 / 2=1.5$} \\
\hline & $\mathrm{V}_{\text {cor }}$ & $\delta_{\text {STD }}$ & $\mathrm{V}_{\text {cor }}$ & $\delta_{\text {STD }}$ & $\mathrm{V}_{\text {cor }}$ & $\delta_{\text {STD }}$ & $\mathrm{V}_{\text {cor }}$ & $\delta_{\text {STD }}$ & $\mathrm{V}_{\text {cor }}$ & $\delta_{\text {STD }}$ & $\mathrm{V}_{\text {cor }}$ & $\delta_{\text {STD }}$ \\
\hline 10 & 1.14 & 0.34 & 1.17 & 0.09 & 1.44 & 0.18 & 0.67 & 0.16 & 1.11 & 0.07 & 1.11 & 0.22 \\
\hline 20 & 0.77 & 0.08 & 1.09 & 0.22 & 1.08 & 0.33 & 1.02 & 0.17 & 1.32 & 0.15 & 1.46 & 0.46 \\
\hline 65 & 0.42 & 0.13 & 0.48 & 0.23 & 0.90 & 0.36 & 0.66 & 0.07 & 0.86 & 0.05 & 0.97 & 0.27 \\
\hline
\end{tabular}

Table III. Percentage and $\mathrm{mg}$ of magnetite in the rusts of the most representative coupons

Tabla III. Porcentaje y mg de magnetita en la herrumbre de los cupones más representativos

\begin{tabular}{|c|c|c|c|c|c|c|c|c|c|c|c|c|}
\hline \multirow{3}{*}{$\begin{array}{c}\text { RECEPTACLE } \\
{[\mathrm{NaCl}] /\left[\mathrm{SO}_{4}^{=}\right]} \\
\text {DAYS }\end{array}$} & \multicolumn{2}{|c|}{2} & \multicolumn{2}{|c|}{1} & \multicolumn{2}{|c|}{3} & \multicolumn{2}{|c|}{4} & \multicolumn{2}{|c|}{5} & \multicolumn{2}{|c|}{6} \\
\hline & \multicolumn{2}{|c|}{$1 / 1.25=0.8$} & \multicolumn{2}{|c|}{1} & \multicolumn{2}{|c|}{1.25} & \multicolumn{2}{|c|}{1.5} & \multicolumn{2}{|c|}{1.75} & \multicolumn{2}{|c|}{$3 / 2=1.5$} \\
\hline & $\%$ & $m g$ & $\%$ & $m g$ & $\%$ & $m g$ & $\%$ & $m g$ & $\%$ & $m g$ & $\%$ & $m g$ \\
\hline 10 & 7.2 & 0.24 & 14.8 & 0.59 & 22.9 & 0.77 & 19.2 & 0.33 & 11.3 & 0.38 & 17.7 & 0.57 \\
\hline 20 & 0 & 0 & 7.2 & 0.31 & 20.1 & 0.71 & 16.2 & 0.75 & 10.4 & 0.49 & 8.5 & 0.37 \\
\hline 65 & 5.6 & 0.34 & 9.8 & 0.91 & 58.0 & 13.3 & 10.2 & 0.34 & 26.2 & 2.33 & 42.9 & 7.76 \\
\hline
\end{tabular}


MSIMM
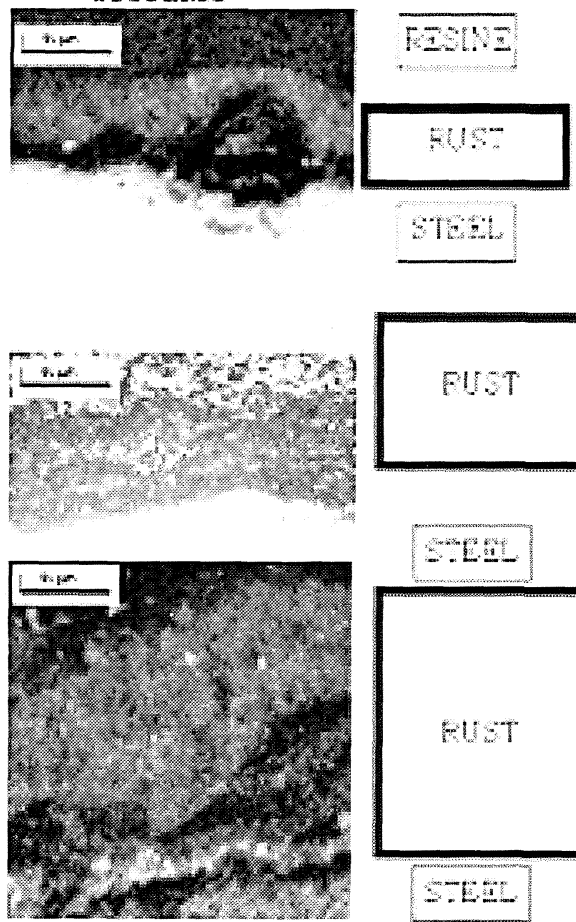

sistmat
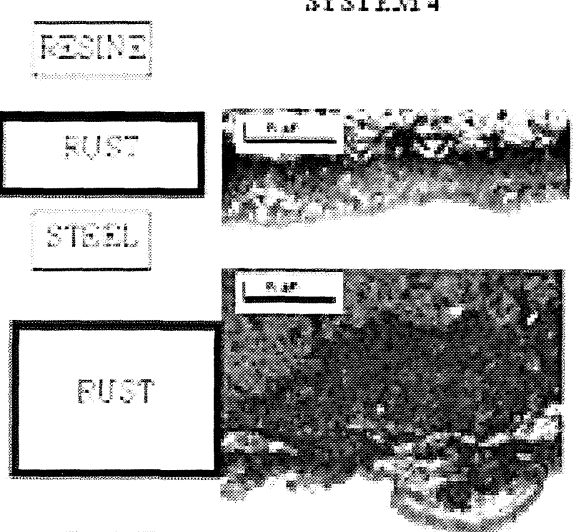

SPTELS

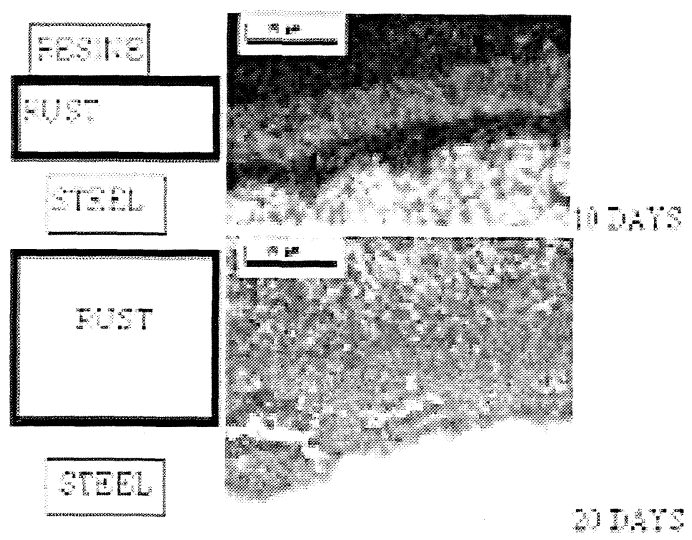

3010

Figure 2. Rust metalography for 3, 4 and 5 systems, at 10, 20 and 65 days. 100X. Polarized light.

Figura 2. Fotomicrografías de las herrumbres de los sistemas 3, 4 y 5 a 10, 20 y 65 días. 100X. Luz polarizada

product of the possible explosions, could be considered having a low $\mathrm{H}_{2} \mathrm{SO}_{4}$ content. On the other hand, in outer areas the enrichment in sulfates due to the explosion, favored goethite formation, in relatively big nuclei.

As the corrosive phenomenon advances, it is observed that the black phase goes from nodules to a homogeneous distribution throughout the metal surface. It is possible to talk of the formation of an inner magnetite layer. Rust external part changes its color, reaching a high lepidocrocite content, which is confirmed by Mössbauer spectroscopy and the metallographic observation for $65 \mathrm{~d}$.

The higher amorphous content in these systems and goethite diminution with time, suggest the existence of a preferential transformation of the initial rust to $\gamma \mathrm{FeOOH}$, restraining the sluggish transformation to magnetite.

It can be say that the nodule preferential growth towards the rust (no concentration), with the subsequent distribution throughout the metal surface (in bands) and a normal conformation of new sulfates nests and goethite niche, are the processes that favored oxygen income, increasing lepidocrocite content and inhibiting magnetite formation.

Group 2, composed by systems 5 and 6, has a higher chloride content in solution. In this group the corrosion rate increasing is reassumed. It was also observed a black phase growth penetrating the metal and an inner white phase intrusion, related to akaganehite formation. As corrosion evolves, these black concentrations start to transform from the center into magnetite, with coloration from dark gray to black.

Chloride higher content favored akaganehite nucleation, allowing white agglomerations, whose size increases with chloride in solution. The low conductivity of this constituent and the shielding effect generated by oxygen income favored magnetite formation in a very localized form. Niche developement is a chloride typical behavior which origins pitting and alveolar corrosion in steel.

Metallographic images for 20 and 65 testing d, show how akaganehite is distributed in the rust. Initially in small brigth agglomerations and then in a massive forma, always surrounded by magnetite. It could be said that magnetite formation occurred in many points in the rust, as a result akaganehite dispersion, which was easily nucleated because higher chloride contents.

Mössbauer spectroscopy registered higher magnetite and lower amorphous contents than in group 1. This indicates that conditions favored 
magnetite formation and inhibited lepidocrocite presence.

Preferential nodule growth toward the metal created attack localization, and the subsequent akaganehite transformation of the rust into a massive form impeded oxygen access, electric conductivity was limited and generated multiple points which favored magnetite formation, inhibiting lepidocrocite.

System 4 presented an intermediate phenomenology between the two already explained groups, even though systems 3 and 5 presented some indications of a similar behavior, specially during the initial exposure periods. The metallographic analysis of this system showed black nodules, similar to those in the second group, but covered or surrounded by a characteristic white phase. On top of this occurs the formation of an intense red phase, which is, in general, related to hydroxides.

Over the sulfate nests akaganehite nuclei appear and salts are formed impeding oxygen (and water) pass and breaking nest film. That created an homogeneous distribution of a great quantity of small places rich in $\mathrm{H}_{2} \mathrm{SO}_{4}$, in which the formation of goethite is promoted.

From the metallographic image is apparent that the evolution with time represented an homogeneous distribution of the black phase nuclei and also of the species related to akaganehite or salt compounds.

Magnetite was in intermediate quantities between the proposed groups and goethite and amorphous $(\gamma)$ compounds increased with time, showing a linearity which has not been detected in the other systems. These situations pointed out some intermediate conditions that favored the formation of all constituents, a fact confirmed with constituents percentages, their evolution with time and the metallographic image for 65 days.

The nest strong explosion due to its membrane breaking generated multiple points that are goethite promoters. The presence of akaganehite distributed in the rust favored magnetite formation. The relatively easy oxygen access, because of the homogeneous distribution of the former constituents, allowed lepidocrocite formation.

Once those three different behaviors or evolutions have been described, it is valid to advance another statement that will be answered, basically, with the previous concepts.

How and why, every mechanism is reflected in a different corrosion rate? Following the methodology of previous section, each group is explained separately.

In group 1 nodules growth was towards the rust, favoring lepidocrocite formation and an homogenous sulfate nest distribution. The evolution of the system generated a uniform magnetite distribution in the inner layer and good oxygenation conditions in every point of the rust layer.

This nodule growth towards the rust oriented the systems for an initial constituents distribution in the rust layer, not in localized form. On the other hand, the existence of homogeneously distributed lepidocrocite created electric conditions that avoided attack localization or preferential formation of any constituent.

The above statements are supported by the preferential growth in the inner rust and a higher distribution density with time. Logically, a more compact rust was formed, adherent and isolating, with a better response to corrosion.

Very localized nodules, which grow towards the metal, favoring magnetite formation in these localized points, are characteristic of group 2 . Other rust zones presented favorable conditions for other constituents.

Because of the localized anodic zones and formation of different constituents at several sites in the rust layer, there were earlier coming up to the surface of the inner layers. This lead to the formation of an heterogeneous rust layer, with different capacities for impeding oxygen pass and different electrical conductivities, thus autocathalizing macrostructure heterogeneity.

Those outcrops lead to an enrichment of loose rust, a lesser increasing in layer density and thicker rust. All this means a layer which is non adherent, porous and with a high capacity to absorb and retain electrolyte, in other words a very poor response to corrosion.

System 4 showed akaganehite, with the already mentioned implication in magnetite formation. Also, there were splashings, rich in $\mathrm{H}_{2} \mathrm{SO}_{4}$, that favored goethite formation in several zones in the rust. The premature distribution of small amounts of akaganeite in the rust, established conditions that favored all sort of constituents.

This proliferation in various points homogeneously enriched the three kinds of rust. Thickness had little increasing, while density increased at constant rate. The formed rust layer had good adherence and isolating capacity.

Electrochemical reactions occurred in the inner layer, without observable localization. In this way, 
Kinetics of structural rust transformation in environments containing chloride and $\mathrm{SO}_{2}$ J.L. RENDÓN AND A. VALENCIA

there were no concentrations or outcrops, giving, as a result, the morphology observed in group 2 coupons.

\section{CONCLUSIONS}

- This work clearly showed the already studied phenomenon in which corrosion rate does not increases, as it should be, when chloride content increases.

- To explain the corrosive mechanism that promoted the different behaviors, systems were classified into three groups. The first one, composed by systems 1,2 and 3 , with the lower chloride content in la solution, was qualified as sulfate rich. The second group had the chloride rich systems 5 and 6 . System 4 was analyzed independently. For group 1 a behavior was proposed that can be generalized to corrosive phenomena when sulfates are present. It favored preferential lepidocrocite and goethite formation. In group 2 it was pointed out how chlorides influence saline nuclei or akaganeite creation, which favored an intensive magnetite formation and inhibited lepidocrocite. System 4 was taken as a intermediate case, with sulfate nests morphology of group one, but without the great concentration of group two. This originated a new phenomenon in nests growth and their dissemination process.

- A kinetic path was shown that lead to protective film formation and the possibility of its manipulation. In that way, in low carbon steels, it is possible to have layers that are especially resistant to corrosion in marine environments. It is easy to imagine the economic implications and the possible new research lines in atmospheric corrosion.

\section{REFERENCES}

[1] INTERNATIONAL ORGANIZATION FOR STANDARDIZATION (ISO 9223), Corrosion of metals and alloys: corrosivity of atmospheres. Classification 1, Ed. Geneve, 1992, p. 16.

[2] M. Morcillo and S. Feliu, Mapas de España de corrosividad atmosférica, CYTED, Madrid, España, 1993, p. 430.

[3] S. Flores, Trabajo de grado, Doctorado en Ciencias Químicas, Facultad de Ciencias Químicas, Universidad Complutense de Madrid, 1994.

[4] R.M. MiRanda, Trabajo de grado, Doctorado en Ciencias Aplicadas, L`Université Libre de Bruxelles, 1974.

[5] F. Corvo, A. Betancourt and A. Mendoza, Influence of airborne salinity on atmospheric corrosion of steel, La Havana, National Centre for Scientific Research, s.f., p. 14.

[6] G. Villa y J. ARIAS, Acción conjunta de los iones $\mathrm{Cl}^{\text {y } \mathrm{SO}_{2} \text { en }}$ la corrosión de un acero de bajo carbono, Facultad de Ingeniería, Universidad de Antioquia, Medellín, 1994.

[7] C. Arroyave, Trabajo de grado, Maestría en Ciencias en Ingeniería Metalúrgica y de Materiales, Universidad Federal de Río de Janeiro, 1988.

[8] A.L. Morales, Hyp. Interac. 28 (1997) 149-154. 